Supporting Information

\title{
Magnetic Colloid Antibodies Accelerate Small Extracellular Vesicles Isolation for Point-of-Care Diagnostics
}

Jingjing Yang ${ }^{\dagger}$, Bei Pan II, Fei Zeng ${ }^{\dagger}$, Bangshun He ${ }^{\text {I, * }}$, Yanfeng Gao ${ }^{\dagger}$, Xinli Liü, Yujun Song ${ }^{\dagger} *$

College of Engineering and Applied Sciences,

Jiangsu Key Laboratory of Artificial Functional Materials,

State Key Laboratory of Analytical Chemistry for Life Science,

National Laboratory of Solid State Microstructures,

Nanjing University

Nanjing 210023, China

Email: ysong@nju.edu.cn

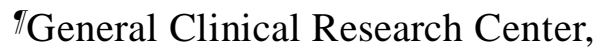

Nanjing First Hospital,

Nanjing Medical University,

Nanjing 211166, China

Email: bhe@njmu.edu.cn 


\section{Experimental Procedures}

1.1 Chemicals and reagents. Tetraethylorthosilicate (TEOS) and 3-aminopropyltriethoxysilane (APTES) were purchased from Sigma-Aldrich (St. Louis, MO, USA). $\mathrm{FeCl}_{3} \cdot 6 \mathrm{H}_{2} \mathrm{O}$, ethylene glycol (PEG 2000), ammonia aqueous solution (28\%), and sodium acetate were purchased from Aladdin (Shanghai, China). Normal Fetal bovine serum (FBS) was purchased from ExCell Bio (Shanghai, China). Exosome-depleted FBS was brought from System Bioscience (SBI, USA). DNase I, RNase, and Micro BCA protein assay was purchased from Thermo Scientific (USA). DNA marker was obtained from Beyotime (Shanghai, China). Tween 20, bovin serum albumin (BSA), PCR primer, and Triton X-100 were obtained from Sangon (Shanghai, China). Glass slides $(75 \times 50 \times 1 \mathrm{~mm})$ were obtained from Corning Inc. (Corning, NY, USA). SPR 220-7 was obtained from MicroChem Corp. (Newton, MA, USA). Silicone oil and hydrogen peroxide $\left(\mathrm{H}_{2} \mathrm{O}_{2}, 35 \%\right.$ w/v in $\left.\mathrm{H}_{2} \mathrm{O}\right)$ were purchased from Sigma-Aldrich (St. Louis, MO, USA). Tridecafluoro-1,1,2,2-tetrahydrooctyl-1trichlorosilane was purchased from Pfaltz and Bauer (Waterbury, CT, USA). Pink ink was purchased from Fisher Scientific (Waltham, MA, USA). Amorphous diamond-coated drill bits were purchased from Harvey Tool (Rowley, MA, USA).

1.2 Instrumentation. The morphology of sEVs was examined by transmission electron microscopy (TEM, Tecnai G2 F20 X-TWIN, FEI, USA). The morphology of MCAs was examined by scanning electronic microscopy (SEM, Tecnai G2 F20 X-TWIN, FEI, USA). The concentrations of RNA and DNA were quantified using the NanoDrop Lite spectrophotometer (Thermo Fisher Scientific). The concentration of vesicles was determined using a NanoSight NS300 System (Malvern).

1.3 Preparation and characterization of the MNPs. The $\mathrm{Fe}_{3} \mathrm{O}_{4}$ particles were prepared through a solvothermal reaction. Briefly, $2.70 \mathrm{~g}$ of $\mathrm{FeCl}_{3} \cdot 6 \mathrm{H}_{2} \mathrm{O}$ and $7.20 \mathrm{~g}$ of sodium acetate were dissolved in $100 \mathrm{~mL}$ of ethylene glycol under magnetic stirring. The obtained homogeneous yellow solution was transferred to a Teflon-lined stainless-steel autoclave and sealed to heat at $200^{\circ} \mathrm{C}$ for $24 \mathrm{~h}$. Then, the obtained black magnetite particles were washed with ethanol for 6 times, and then dried in vacuum at $60^{\circ} \mathrm{C}$ for $12 \mathrm{~h}$.

The core-shell $\mathrm{Fe}_{3} \mathrm{O}_{4} @ \mathrm{SiO}_{2}$ particles (MNPs) were prepared via a modified Stöber sol-gel process. ${ }^{1,2}$ Briefly, $0.10 \mathrm{~g}$ of $\mathrm{Fe}_{3} \mathrm{O}_{4}$ particles ( $400 \mathrm{~nm}$ in diameter) were homogeneously dispersed in the mixture of ethanol $(80 \mathrm{~mL})$, deioned (DI) water $(20 \mathrm{~mL})$ and concentrated ammonia aqueous solution $(1.0 \mathrm{~mL}, 28 \mathrm{wt} . \%)$, followed by the addition of TEOS $(0.8 \mathrm{~mL})$. After stirring at room temperature for $12 \mathrm{~h}$, the $\mathrm{Fe}_{3} \mathrm{O}_{4} @ \mathrm{SiO}_{2}$ microspheres were collected with a magnet and washed repeated with ethanol and water.

1.4 Cell culture. A549, MDA-MB-231 and CaOV3 cell lines were purchased from the American Type Culture Collection (ATCC). All cell lines were cultured at $37^{\circ} \mathrm{C}$ under a $5 \%$ humidified $\mathrm{CO}^{2}$ atmosphere and maintained in Dulbecco's Modified Eagle's medium (DMEM) supplemented with $10 \%$ FBS (ExCell Bio).

1.5 Preparation and characterization of model samples of sEV. Cells were grown in nine T75 flasks (Corning) for two to three days until they reached a confluency of $80 \%$. Next, cells were cultured in DMEM supplemented with 10\% exosome-free FBS for $48 \mathrm{~h}$. The medium was collected and centrifuged at $300 \mathrm{~g}$ for $5 \mathrm{~min}$ followed by a centrifugation step at $16,500 \mathrm{~g}$ for $20 \mathrm{~min}$ to discard 
cellular detritus. Afterwards, the medium was filtered using a $0.22 \mu \mathrm{m}$ (pore size) filter. Subsequently, medium was collected and continuously ultracentrifuged at 100,000 g for $90 \mathrm{~min}$ at $4^{\circ} \mathrm{C}$. The pellets of sEVs were washed with cold PBS once, followed by a second ultracentrifugation. The model sEVs were incubated with $10 \mu \mathrm{L}$ of DNase I ( 1 units $\mu \mathrm{L}^{-1}$; Life Technologies) or $5 \mu \mathrm{g} \cdot \mathrm{ml}^{-}$ ${ }^{1}$ RNase (Beyotime) at $37{ }^{\circ} \mathrm{C}$ for $2 \mathrm{~h}$. The obtained sEVs were collected and stored at $-80^{\circ} \mathrm{C}$ for further treatment.

Isolated sEVs were characterized with nanoparticle tracking analysis (NTA) using NanoSight NS300 (Malvern Instruments) to determine the size and concentrations. The protein concentration was measured using a micro BCA protein assay (Thermo Scientific). For TEM, sEV sample ( $5 \mu \mathrm{L}$ ) was placed on a copper grid and followed by standard procedures for fixing and dehydrating sEV samples as described in previous report. ${ }^{3}$

1.6 MCAs synthesis. To functionalize the MNPs with amino groups, $18 \mathrm{~mL}$ of MNPs $\left(3.2 \mathrm{mg} \cdot \mathrm{mL}^{-}\right.$ $\left.{ }^{1}\right)$ and $11 \mu \mathrm{L}$ of APTES were ultrasonically dispersed in water. After an ultrasonic treatment for 30 min, the products were collected, thrice rinsed with DI water, and then incubated in $18 \mathrm{~mL}$ of $1 \%$ (v/v) aqueous glutaraldehyde solution for $30 \mathrm{~min}$. After washing with DI water for three times, template $\mathrm{sEVs}\left(25 \mu \mathrm{g} \cdot \mathrm{mL}^{-1}, 2 \mathrm{~mL}\right)$ were then incubated with the MNPs $\left(1 \mathrm{mg} \cdot \mathrm{mL}^{-1}, 10 \mathrm{~mL}\right)$ for $2 \mathrm{~h}$ under shaken condition ( $300 \mathrm{rpm}$ ) in glass vials. Subsequently, 12 or $18 \mu \mathrm{L}$ of TEOS were added to the reaction mixture and allowed to react for $2 \mathrm{~h}$ at $20^{\circ} \mathrm{C}$ to produce MCAs and MCATEOS, respectively. Temperature was then lowed to $10^{\circ} \mathrm{C}$, and $9 \mu \mathrm{L}$ of APTES was added to prepare particles with recognition layers (MCAs). No additional organosilane was added during the preparation of MCAтеоs. Sample were collected at increasing reaction times by magnetic separation. The MNP ${ }_{\text {AT }}$ were produced in a similar fashion with MCAs by omitting the SEV addition step.

Afterwards, the MCAs were suspended in the removal solution $(0.01 \mathrm{M} \mathrm{HCl}$ and $0.01 \% \mathrm{v} / \mathrm{v}$ Triton-X 100) and subjected to an ultrasonic treatment for $10 \mathrm{~min}$. Then, the MCAs suspensions were incubated at $40^{\circ} \mathrm{C}$ for $30 \mathrm{~min}$ with continuous stirring ( $300 \mathrm{rpm}$ ). Subsequently, the so-treated MCAs were submitted to an additional ultrasonic treatment for $5 \mathrm{~min}$, washed by DI water and collected by magnetic separation. The morphology of the MCAs at different process was examined using a SEM (Ultra Plus, Zeiss, Germany).

$1.7 \mathrm{sEV}$ binding assay. In the binding assay, MCAs with a $21-\mathrm{nm}$ recognition layer were selected. Before used, the MCAs were blocked with 0.1\% BSA solution and washing with DI water for three times. In a typical experiment, sEVs in PBS were mixed with the MCAs at a final concentration of $25 \mu \mathrm{g} \cdot \mathrm{mL}^{-1}$. Then the reaction medium was shaken at $300 \mathrm{rpm}$ for different times. After the desired contact time, captured sEVs were pull down with a magnet, and gently resuspended in $100 \mu \mathrm{L}$ PBS for downstream analysis. Meanwhile, the supernatant was collected for sEV quantification by micro BCA protein assay (Thermo Scientific) performed following the manufacturer's protocol. The measured values were compared with a standard curve of defined amounts of sEVs dissolved in PBS and measured by micro BCA protein assay.

The morphology of the MCAs after sEV binding was examined using a SEM (Ultra Plus, Zeiss, Germany). After sEV binding assay, the particles were collected and washed with PBS for twice. Subsequently, the obtained particles were fixed in $4 \%$ paraformaldehyde for $2 \mathrm{~h}$, and then dehydrated in a series of increasing ethanol concentrations. The obtained samples were imaged with a SEM (ULTRA Plus, Zeiss, Germany). 
1.8 Adsorption experiments. MCAs or control $\mathrm{MNP}_{\mathrm{AT}}(10 \mathrm{mg})$ was mixed with $2 \mathrm{~mL}$ of $\mathrm{sEV}$ solution for different final concentrations from 2.5 to $25 \mu \mathrm{g} \cdot \mathrm{mL}^{-1}$, which were shaken in an incubator shaker ( $300 \mathrm{rpm}$ ) at $25^{\circ} \mathrm{C}$ for 20 minutes. The saturated MCAs were separated with an external magnet. And the residual sEVs in the supernatant were measured by micro BCA protein assay. The binding capacities $\left(Q_{e}, \mu \mathrm{g} \cdot \mathrm{mg}^{-1}\right)$ of MCAs and $\mathrm{MNP}_{\mathrm{AT}}$ for the template sEVs were calculated using the following formula:

$$
Q_{e}=\left(C_{0}-C_{e}\right) V / M
$$

where $C_{0}$ and $C_{e}$ (in $\mu \mathrm{g} \cdot \mathrm{mL}^{-1}$ ) are the initial and equilibrium concentrations of $\mathrm{sEV}$ in solution, respectively, $V$ (in $\mathrm{mL}$ ) is the total volume of the solution, and $M$ (in $\mathrm{mg}$ ) is the adsorbent mass.

The equilibrium data were analyzed according to the linear form of the Langmuir sorption isotherm as:

$$
C_{e} / Q_{e}=1 /\left(Q_{\max } * K_{L}\right)+C_{e} / Q_{\max }
$$

where $Q_{e}\left(\mathrm{mg} \cdot \mathrm{g}^{-1}\right)$ is the amount of sEVs adsorbed at equilibrium, $Q_{\max }\left(\mathrm{mg} \cdot \mathrm{g}^{-1}\right)$ is the apparent maximum adsorption capacity, $C_{e}\left(\mathrm{mg} \cdot \mathrm{L}^{-1}\right)$ is the equilibrium concentration of sEVs in solution, $K_{L}$ $\left(\mathrm{L} \cdot \mathrm{mg}^{-1}\right)$ is the dissociation constant of Langmuir Equation. The value of $Q_{\max }$ and $K_{L}$ can be calculated from the slope and intercept of the linear plot of the $C_{e} / Q_{e}$ versus $C_{e}$.

The Freundlich model was also tested to describe the sorption data. The linear representation of the Freundlich adsorption equation is:

$\log Q_{e}=\log K_{F}+\log C_{e} / \mathrm{n}$

where $K_{F}$ and $\mathrm{n}$ are the Freundlich constants, which affects the adsorption capacity and the intensity of the adsorption, respectively. The value of $K_{F}$ and n can be calculated from the slope and intercept of the linear plot of the $\log Q_{e}$ versus $\log C_{e}$.

1.9 Nucleic acid and protein extraction. Culture media form $\mathrm{CaOV} 3$ cells $(50 \mathrm{~mL})$ was incubated with MCAs (15 mg) and reacted for 20 minutes to isolated CaOV3 derived sEVs. After sEV binding assay, the obtained sEVs were incubated with $10 \mu \mathrm{L}$ of DNase I ( 1 units $\mu \mathrm{L}^{-1}$; Life Technologies) or $5 \mu \mathrm{g} \cdot \mathrm{ml}^{-1}$ RNase at $37{ }^{\circ} \mathrm{C}$ for $2 \mathrm{~h}$ before nucleic acid extraction. Then, the isolated sEVs were lysed by immersing into Trizol (Life Technologies), RNA was extracted from lysates according to the manufacturer's instructions. Trizol $(750 \mu \mathrm{L})$ and chloroform $(200 \mu \mathrm{L})$ were added to and vigorously mixed with MCAs $(15 \mathrm{mg})$. After MCAs removed by a magnet, the aqueous phase of the sample was homogenized with $500 \mu \mathrm{L}$ of pure isopropanol and pelletized. This was followed by an RNA wash using $1 \mathrm{ml}$ of $75 \%$ ethanol. Finally, the RNA pellet was dissolved in $10 \mu \mathrm{L}$ of RNasefree water. The RNA concentrations were quantified with Nanodrop spectrophotometer (Thermo Scientific).

The DNA was extracted using the QIAamp DNA micro kit (Qiagen, Germany) according to the manufacturer's instructions. Briefly, proteinase $\mathrm{K}(10 \mu \mathrm{L})$ and lysis buffer $(100 \mu \mathrm{L})$ were added to conduct DNA extraction of sEVs from the MCAs $(15 \mathrm{mg})$. Then free MCAs were removed by magnet separation, and the supernatant was collected. After heat inactivation at $56^{\circ} \mathrm{C}$ for $10 \mathrm{~min}$, $100 \mu \mathrm{L}$ of pure ethanol was added to the supernatant. The whole volume was centrifuged in a spin column. After two washing steps, the DNA was eluted in $50 \mu \mathrm{L}$ of AE buffer and stored at $-20{ }^{\circ} \mathrm{C}$ until PCR amplification. The DNA concentrations were quantified with Nanodrop spectrophotometer (Thermo Scientific). DNA and RNA extracted from isolated sEVs were identified with $2 \%$ agarose gel electrophoresis. DNA ladders (1 kbp) was used to indicate the length of the fragments.

To monitor protein expression, $5 \%$ Triton X-100 was added to the MCAs after binding assay to 
extract SEV protein. The sEVs' proteins were collected and separated using 10\% SDS-PAGE. Followed by transferring onto PVDF membranes, the blots were first blocked with $2 \%$ BSA solution, then incubated overnight at $4{ }^{\circ} \mathrm{C}$ in primary antibody $(1: 1000)$. The membranes were washed six times ( $1 \times$ PBS and $0.5 \%$ Tween 20, pH 7.4), and then immerged into HRP-conjugated secondary antibodies (Sangon Biotech) for $1 \mathrm{~h}$ at room temperature. Afterwards, the washing step was repeated six times in washing buffer and targeted proteins were visualized by W-TMB (Beyotime). Information about the primary antibodies was included in Supplementary Table 2.

After nucleic acid and protein extraction, MCAs were washed with ethanol and water for three times, and prepared for next cycle. The binding-releasing-washing cycle was repeated for 5 times.

1.10 Immunofluorescence staining. Biotinylated monoclonal anti-CD63, anti-CD24, and antiEpCAM were added to sEV-MCAs complex after binding assay and incubated overnight at $4^{\circ} \mathrm{C}$. Then, FITC-conjugated streptavidin (BD Biosciences) diluted in PBS containing 0.1\% BSA was then added and incubated for $1 \mathrm{~h}$ at room temperature. Finally, the labelled MCAs were examined using fluorescence microscope (EVOS EL AUTO). Information about the primary antibodies was included in Supplementary Table 2.

1.11 PCR (Polymerase Chain Reaction) and sequencing. KRAS analysis (466 bp) was performed using the following primers: forward 5'-AAG GCC TGC TGA AAA TGA CTG-3' and reverse 5'TCA CAA TAC CAA GAA ACC CAT- 3 '. The PCR was performed as previous report. ${ }^{4} \mathrm{PCR}$ products were cleaned using a QIAquick PCR Purification Kit (Qiagen) following the manufacturer's instructions, and then sequenced by Sanger DNA sequencing (Applied Biosystems 3730XL).

1.12 Preparation of the Pt NP probes. Pt NPs with an average diameter of $22 \mathrm{~nm}$ were prepared by modifying the previously reported methods. ${ }^{5}$ To prepared antibody conjugated Pt NPs, $10 \mu \mathrm{L}$ of monoclonal antibody $\left(1 \mathrm{mg} \cdot \mathrm{mL}^{-1}\right)$ was mixed with $500 \mu \mathrm{L}$ of Pt NPs $\left(1 \mathrm{mg} \cdot \mathrm{mL}^{-1}\right)$ in Tris buffer $(\mathrm{pH}$ 7.4, $20 \mathrm{mM}$ ), which was kept at $4^{\circ} \mathrm{C}$ for overnight. Next, BSA was added to block the surface of Pt NPs with the final concentration of $1 \%$ and the unconjugated antibody was removed by dialysis. Finally, the antibody conjugated Pt NPs were suspended in $500 \mu \mathrm{L}$ PBS $(10 \mathrm{mM}, \mathrm{pH} 7.2,0.1 \%$ Triton X-100, $5 \%$ sucrose, $1 \%$ BSA).

1.13 Preparation of V-Chip. Methods for V-Chip production can be found from our previous publications. ${ }^{6,7}$ Briefly, the pattern for the V-Chip was fabricated using a standard photolithography process, with the procedures as shown in Figure S7. In brief, glass slides $(75 \times 50 \times 1 \mathrm{~mm})$ were first spin-coated with a layer $(\sim 10 \mu \mathrm{m})$ of SPR220-7 photoresist, baked at $75^{\circ} \mathrm{C}$ for $3 \mathrm{~min}$, and baked again at $110^{\circ} \mathrm{C}$ for $5 \mathrm{~min}$. After cooling to room temperature, the photoresist-coated glass slides were exposed to UV light for $50 \mathrm{~s}$ through a photomask containing the V-Chip layout. Slides were then immersed in SPR developer solution (MF-CD26) for 3 min to wash the photoresist off the exposed area. Slides were then thoroughly rinsed with DI water and dried with nitrogen gas to create the pattern. Before etching, the backs of the slides were protected with polyvinyl chloride sealing tape to prevent unintentional etching. The glass slides were then immersed in a glass-etching solution (1:0.5:0.75 mol/ $\left.\mathrm{L} \mathrm{HF} / \mathrm{NH}_{4} \mathrm{~F} / \mathrm{HNO}_{3}\right)$ to etch the pattern. Etching was performed in a $35^{\circ} \mathrm{C}$ water bath to control the etching speed. After $45 \mathrm{~min}$, slides were etched to a depth of $\sim 30 \mu \mathrm{m}$. The 
sealing tape was removed and slides were rinsed with water and acetone and wiped with ethanol cloth. Finally, holes for sample inlets/outlets were formed with a 0.03 -inch diamond drill. For surface modification, the glass slides were first treated with oxygen plasma followed by deposition of $10 \mu \mathrm{L}$ tridecafluoro-1, 1, 2, 2-tetrahydrooctyl-1-trichlorosilane and drying in a vacuum drier for $2 \mathrm{~h}$. Finally, the glass slides were wiped with ethanol cloth and dried with nitrogen gas.

\subsection{On-chip detection.}

The CaOV3 derived sEVs were collected by ultracentrifugation and further serially diluted to gradient concentrations. Then, the diluted sEVs $(1 \mathrm{~mL})$ were incubated with MCAs (1 mg) and shaken at $300 \mathrm{rpm}$ for $20 \mathrm{~min}$. After washing with PBS for three times to remove the unbound sEVs, the sEV-MCAs complex was blocked with BSA $(0.1 \%)$ and then incubated with antibody (CD63, CD24 and EpCAM) conjugated Pt NPs for $1 \mathrm{~h}$ at room temperature. Finally, the resulting product was washed three times with PBS and concentrated to $50 \mu \mathrm{L}$, and then added to a V-Chip for sEV quantitative detection. In the absence of sEVs, the response comes from non-specific binding. Therefore, a control channel was included in all the multiplex assays.

As for animal plasma samples detection, MCAs were made by template sEVs derived by CAOV 3 cells. As for clinical samples detection, MCAs were made by mixed template sEVs that isolated from 10 samples. Afterwards, diluted plasma was incubated with the MCAs and shaken at $300 \mathrm{rpm}$ for $20 \mathrm{~min}$. After washing with PBS for three times, the sEV-MCAs complex was blocked with BSA $(0.1 \%)$ and then incubated with antibody coating Pt NPs for $1 \mathrm{~h}$ at room temperature. Finally, the resulting product was washed three times with PBS and added to a V-Chip for quantitative detection. The readout was recorded in $10 \mathrm{~min}$ after initiation of the reaction by sliding of the top plate. Each sample was assayed in triplicate to determine the mean and SD (error bars).

1.15 Animal experiments. In the xenograft mouse model of human ovarian cancer, $\mathrm{CaOV} 3(5 \times$ $10^{6}$ cells/mouse) were subcutaneously injected into female BALB/c mice $(n=6)$ of 6 -week old. The tumor sizes were measured using a caliper. Tumor volume was calculated using the formula: (length $\times$ width $\left.^{2}\right) / 2$. Then, $\sim 50 \mu \mathrm{L}$ blood was collected from tail veins of mice weekly with the EDTAcoated tubes and plasma was immediately prepared for on-chip sEV analysis. Animal procedures were performed according to the guidelines of the Institutional Animal Care and Use Committee of the Nanjing Drum Tower Hospital, the Affiliated Hospital of Nanjing University Medical School. For microfluidic analysis, plasma was diluted with PBS by 200 times and used without any further pre-treatment.

1.16 Clinical samples. Human plasma samples were collected at the Nanjing Drum Tower Hospital. The study was approved by the Ethics Committee of Nanjing Drum Tower Hospital, the Affiliated Hospital of Nanjing University Medical School. All patients enrolled were given informed written consent. All samples were anonymised, and only the gender, age and pathological diagnosis were recorded. For microfluidic analysis, plasma was diluted with PBS by 2000 times and used without any further pre-treatment. sEV assay and data acquisition followed the same processes as for $\mathrm{SEV}$ standards. 
1.17 Statistical analysis. Mean, SD, SEM, and LOD were calculated with standard formulas. Deming linear fitting was performed at the $95 \%$ confidence level to determine the Pearson correlation coefficient between different variables. For mouse models, $P$ values were determined by one-way repeated measures ANOVA with post hoc Tukey's pairwise multiple comparisons test. For human specimen, the significance of two clinical serum sample groups was tested using a nonparametric, two-tailed Mann-Whitney $U$-test. Significance analyses, receiver operator characteristic (ROC) curve construction and the areas under the curves (AUC) calculation were performed using GraphPad Prism 7.

\section{Results and Discussion}

A

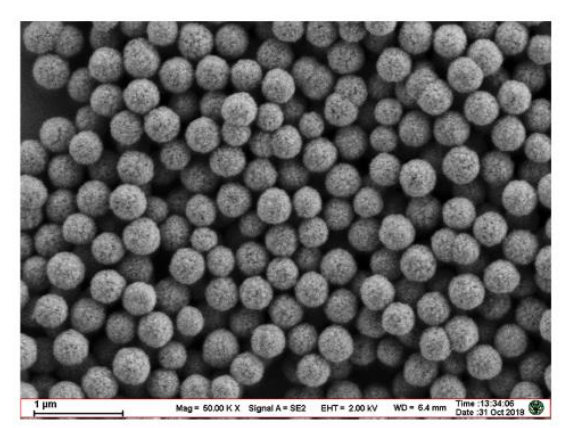

C

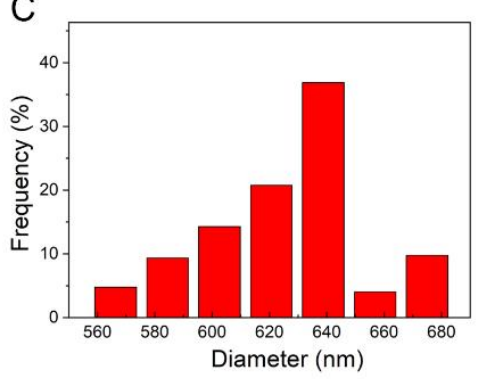

$\mathrm{D}$

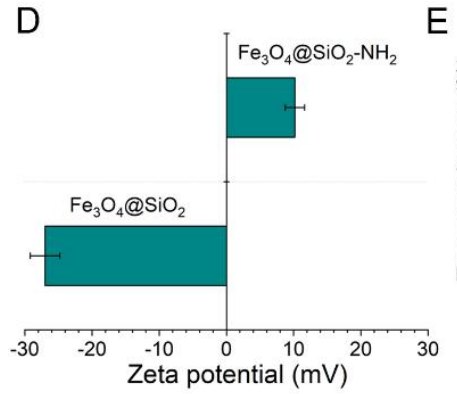

E
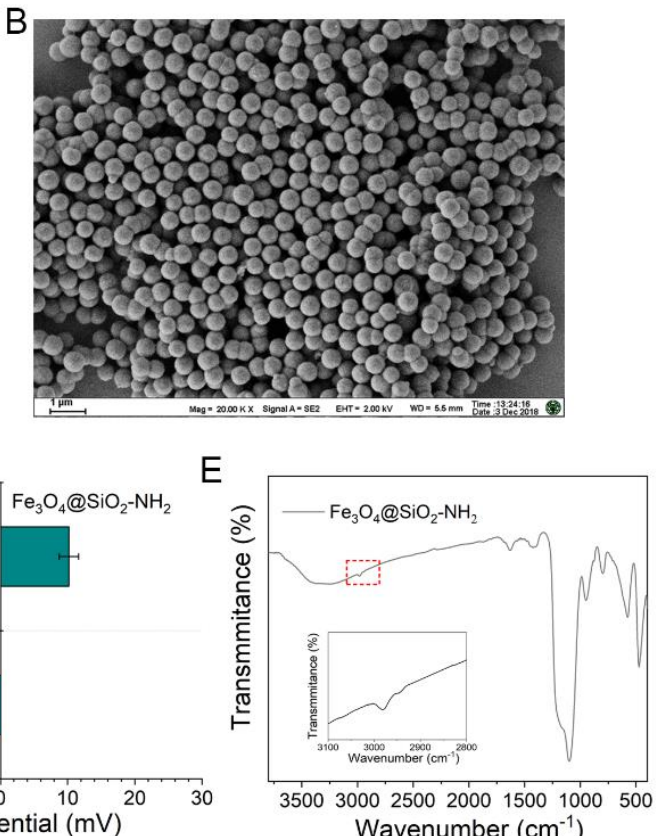

Figure S1. Characterization of MNPs. A) SEM image of $\mathrm{Fe}_{3} \mathrm{O}_{4}$ core and B) $\mathrm{Fe}_{3} \mathrm{O}_{4} @ \mathrm{SiO}_{2}$. C) Size distribution of MNPs. D) Zeta potentials of $\mathrm{Fe}_{3} \mathrm{O}_{4} @ \mathrm{SiO}_{2}$ and $\mathrm{Fe}_{3} \mathrm{O}_{4} @ \mathrm{SiO}_{2}-\mathrm{NH}_{2}$. After APTES modification, zeta potential of the MNPs changed from $-27.0 \mathrm{mV}$ to $+10.2 \mathrm{mV}$. E) FTIR of $\mathrm{Fe}_{3} \mathrm{O}_{4} @ \mathrm{SiO}_{2}-\mathrm{NH}_{2}$. The absorption peaks at $\sim 2967 \mathrm{~cm}^{-1}\left(\mathrm{CH}_{2}\right.$ asymmetric stretching) and $2850 \mathrm{~cm}^{-1}\left(\mathrm{CH}_{2}\right.$ symmetric stretching $)$ which were assigned to the stretching vibration of methylene groups, suggesting the successful immobilization of amine groups on the surface of MNPs. 


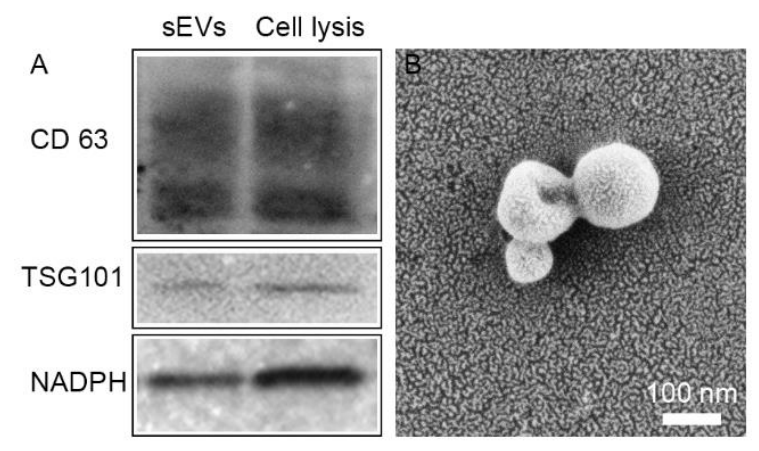

Figure S2. A) Western blot of sEVs and cell lysis from CaOV3. B) SEM image of CaOV3 derived sEVs.
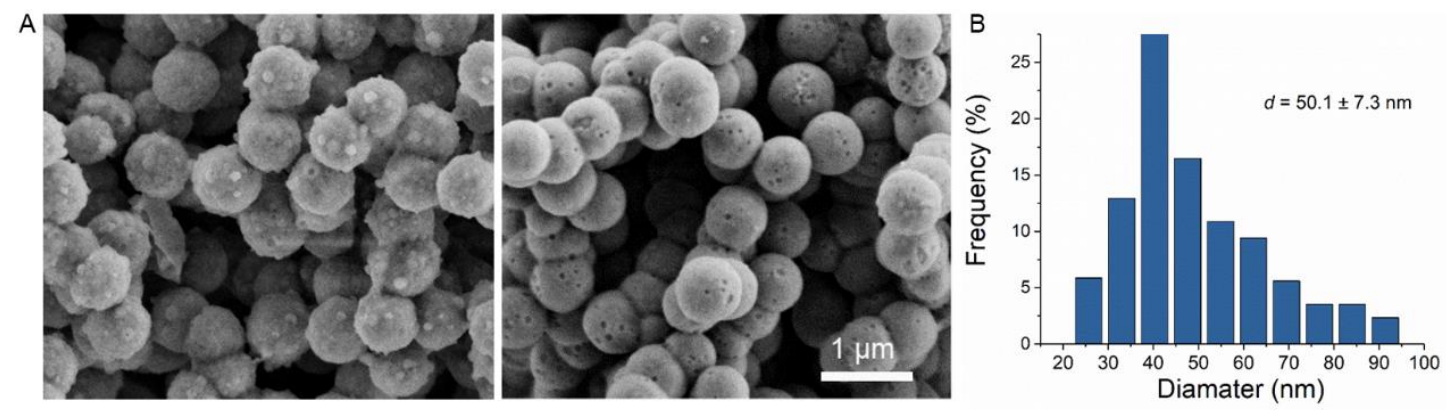

Figure S3. A) SEM images of MCAs before (left) and after (right) ultrasonic treatment at a large scale and B) the corresponding size distribution of the surface cavities. 

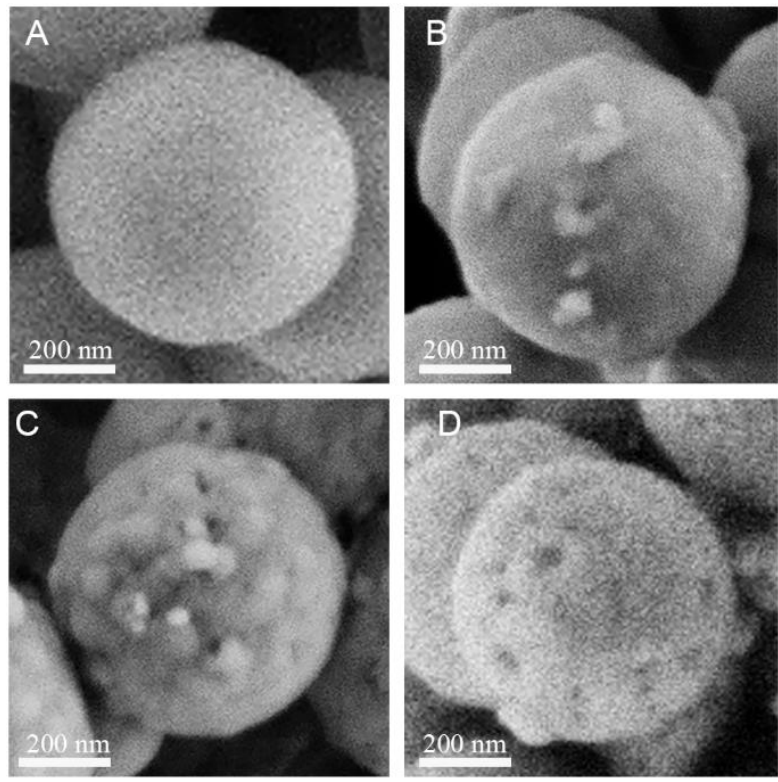

Figure S4. SEM images of MCAs at different stages made from MDA-MB-231 cell-derived sEVs. A) MNPs, B) immobilization of template sEVs at the surface of MNPs, C) addition of organosilanes to build the recognition layer, D) removal of immobilized sEVs to free the sEV imprints.
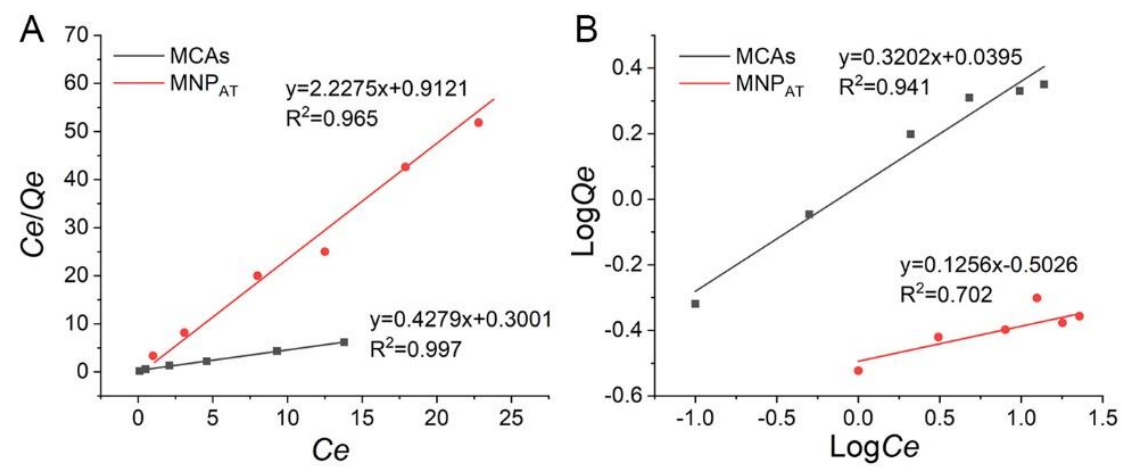

Figure S5. A) The Langmuir and B) Freundlich adsorption isotherm models of $\mathrm{MNP}_{\mathrm{AT}}$ and MCAs. It is noted that the Langmuir isotherm model gives a better fit for sEV adsorption on MCAs than Freundlich model, suggesting that the binding sites formed by the template are homogeneous in respect to the affinity for sEVs. 


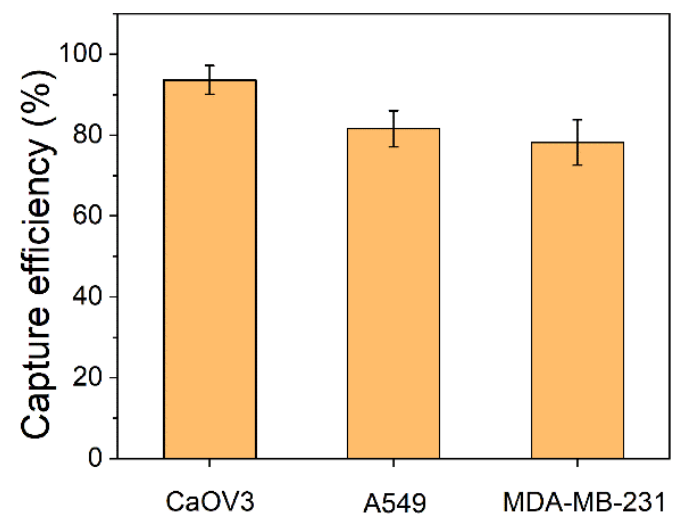

Figure S6. Capture efficiency of CaOV3, A549 and MDA-MB-231 cell-derived sEV s by $\mathrm{CaOV} 3$ cell-derived sEV s templated MCAs, respectively.

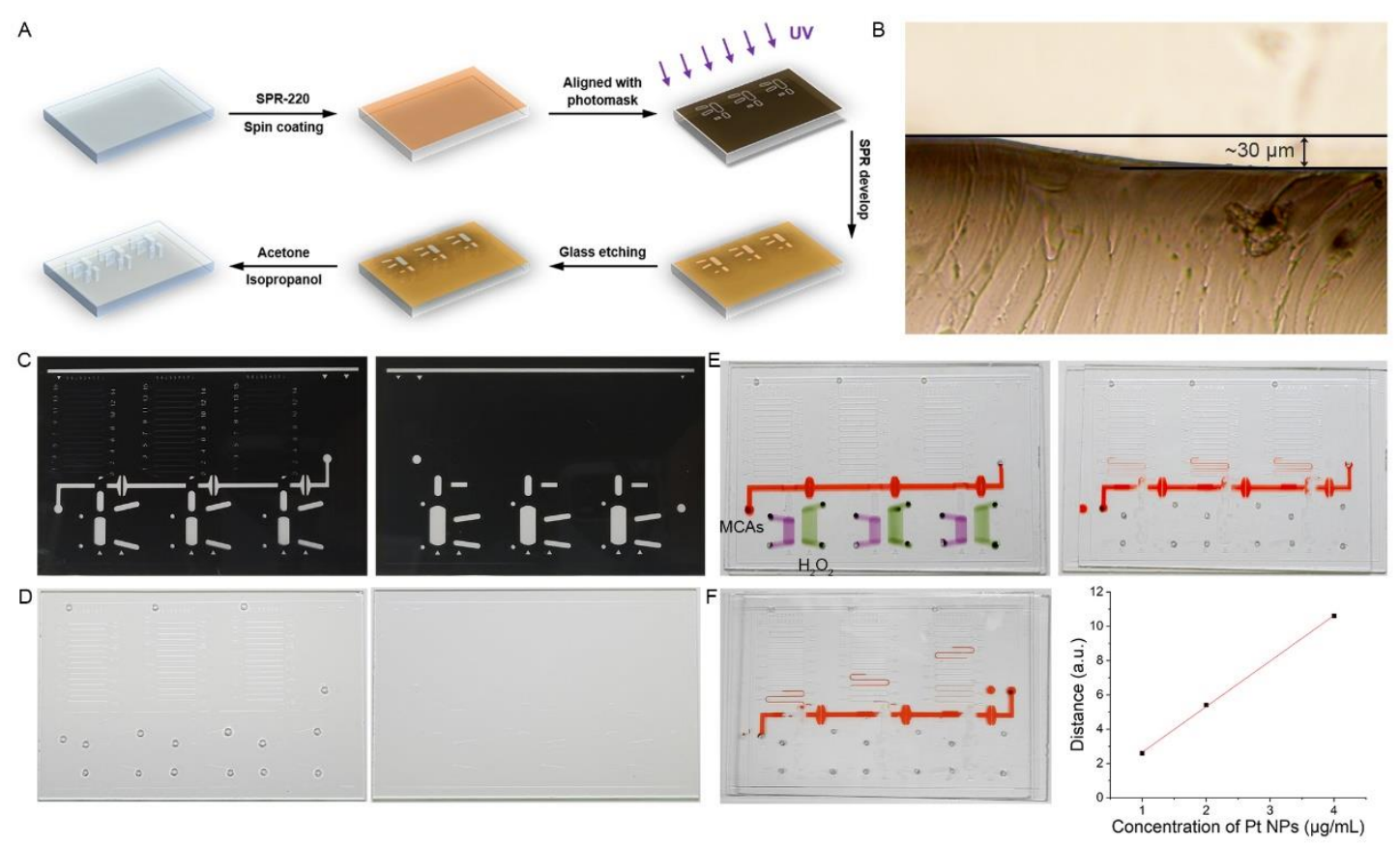

Figure S7. Fabrication of V-Chip. A) Schematic diagram of the fabrication processes of V-Chip. B) Channel depth measurement. Polydimethylsiloxane elastomer was adopted to replicate the channels on the glass slide for the channel depth measurement. All V-Chip devices in this paper are approximately 30 micrometers. C) Masks used for the preparation of V-Chip, top plate (left) and bottom plate (right). D) Photographs of V-Chip, top plate (left) and bottom plate (right). E) Photographs of a typical assembled and loaded V-Chip (left). Photograph of V-Chip after loading Pt NPs with the same concentration into three reaction wells (right). It can be clearly observed that the three units formed almost equal distances of ink bars when they were loaded with Pt NPs at the same concentration, suggesting that the V-Chip could be used for multiplexed detection. F) Photograph (left) and the corresponding diagram (right) of loading Pt NPs with gradient concentrations. When a series of Pt NPs solutions $\left(1,2\right.$ and $\left.4 \mu \mathrm{g} \cdot \mathrm{mL}^{-1}\right)$ were employed, the distances of the ink-bar correspond to the concentration of Pt NPs, suggesting that this VChip could be used for quantitative detection. 

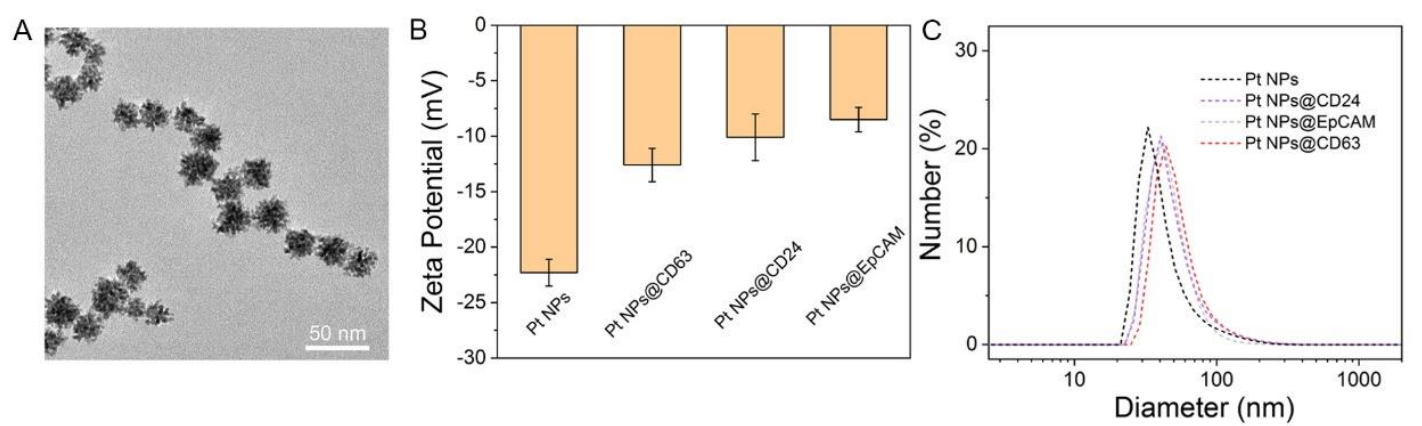

Figure S8. A) TEM image of Pt NPs. B) Zeta potential and C) hydrodynamic diameters of Pt NPs, CD63, CD24, and EpCAM conjugated Pt NPs, respectively. The change of zeta potential and the increase of hydrodynamic diameter of antibody modified Pt NPs proved the successful formation of Pt probe.

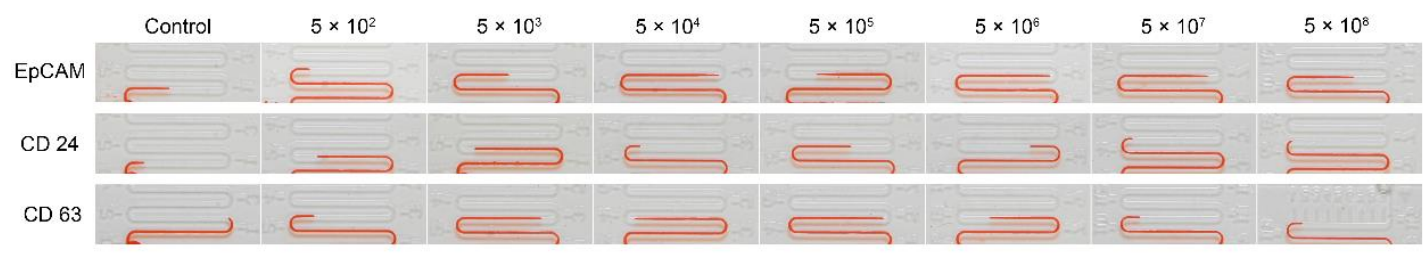

Figure S9. Photographs of visual ink-bar charts at a gradient concentration of $\mathrm{CaOV} 3$ derived sEVs corresponding to calibration curves of EpCAM, CD24, and CD63 expression on the surface of sEVs in Figure. 4B. 


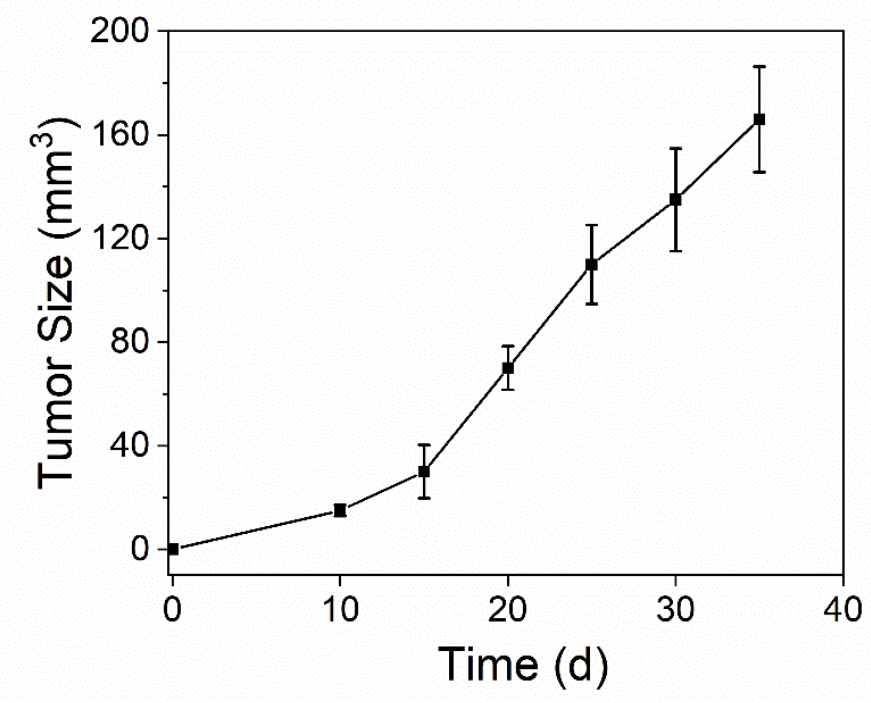

Figure S10. Growth of subcutaneously xenografted tumors in mice. Size of primary tumor in each mouse was measured with a caliper and the tumor volume was calculated using the modified ellipsoidal formula: $\left(\right.$ length $\times$ width $\left.^{2}\right) / 2$.
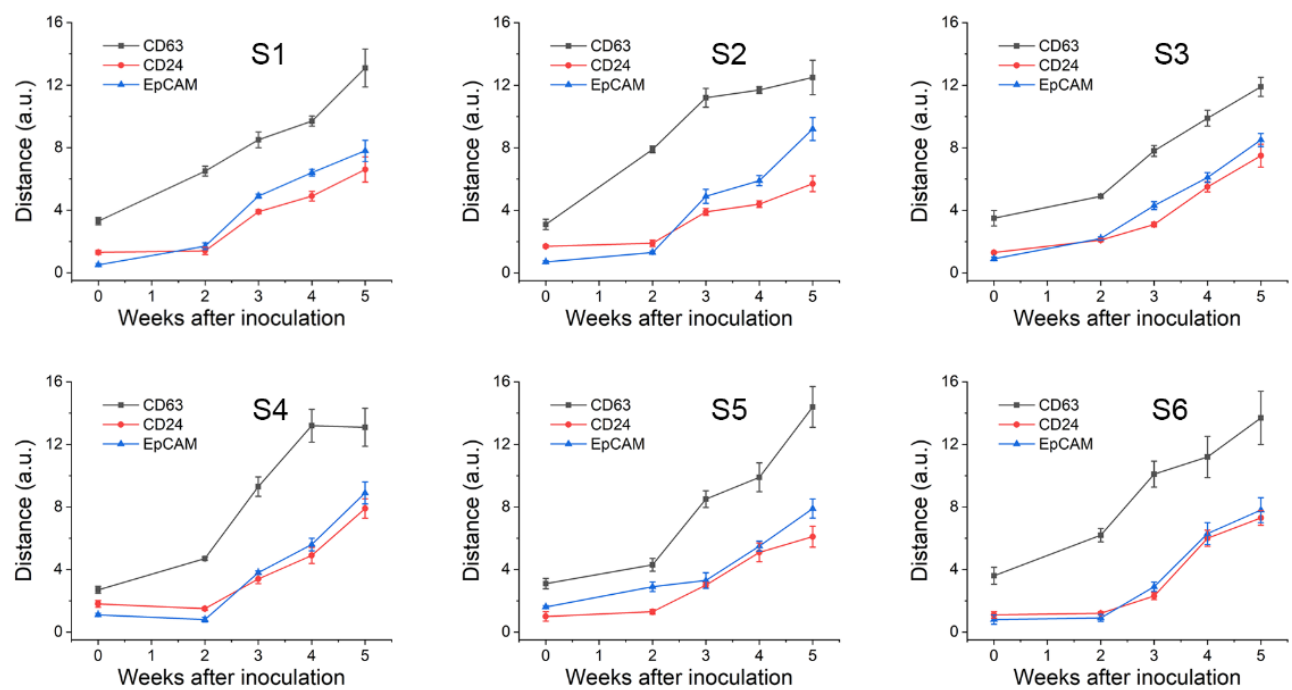

Figure S11. Time-lapse, multi-parametric measurements of sEVs in 6 mice using the MV-Chip technology. 


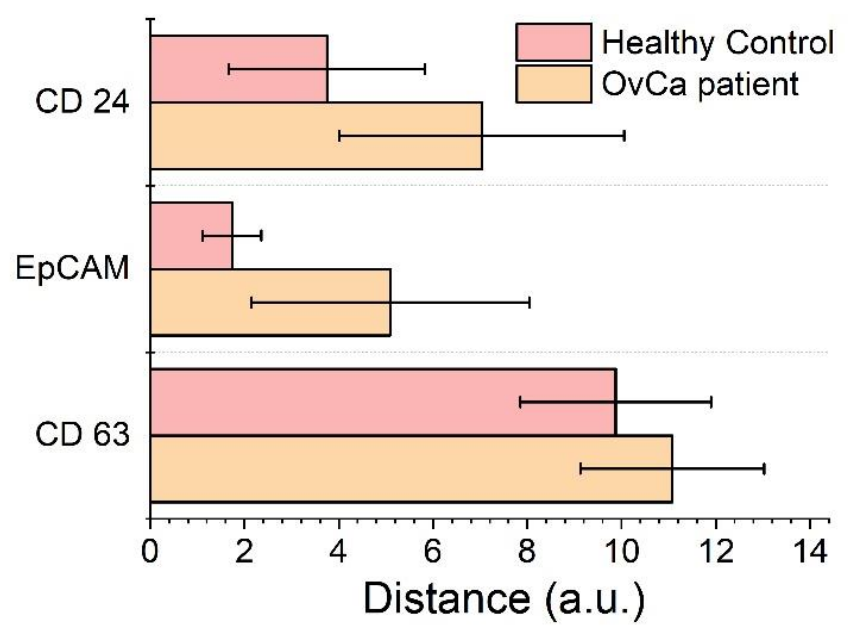

Figure S12. Average expression levels of individual sEV maker for OvCa patients and healthy controls.
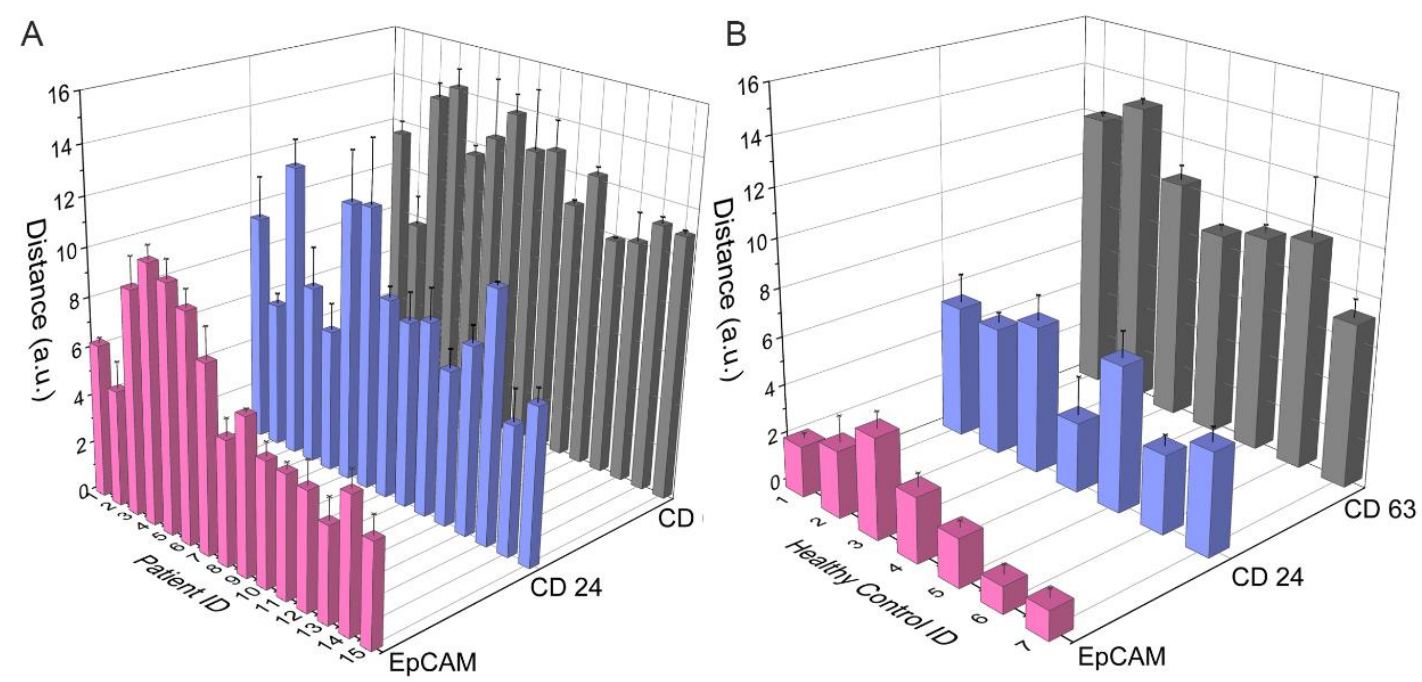

Figure S13. Measurement of individual sEV marker expression levels for A) OvCa patients and B) healthy controls. 
Table S1. Accuracy classification by AUC for a diagnostic test.

\begin{tabular}{|l|l|}
\hline AUC Range & Classification \\
\hline $0.9<$ AUC $<1.0$ & Excellent \\
\hline $0.8<$ AUC $<0.9$ & Good \\
\hline $0.7<$ AUC $<0.8$ & Worthless \\
\hline $0.6<$ AUC $<0.7$ & Not good \\
\hline
\end{tabular}

Table S2. Information about the primary antibodies.

\begin{tabular}{|l|l|}
\hline Type & Brand \\
\hline Biotin anti-human CD63 Antibody & BioLegend \\
\hline Biotin anti-human CD24 Antibody & BioLegend \\
\hline Biotin anti-human EpCAM Antibody & BioLegend \\
\hline Anti-human CD63 Antibody & BioLegend \\
\hline Anti-human CD24 Antibody & BioLegend \\
\hline Anti-human EpCAM Antibody & BioLegend \\
\hline Anti-human TSG 101 Antibody & Abcam \\
\hline Anti-human GAPDH Antibody & Abcam \\
\hline
\end{tabular}

\section{Reference}

1. Deng, Y.; Qi, D.; Deng, C.; Zhang, X.; Zhao, D. Superparamagnetic high-magnetization microspheres with an $\mathrm{Fe}_{3} \mathrm{O}_{4} @ \mathrm{SiO}_{2}$ core and perpendicularly aligned mesoporous $\mathrm{SiO}_{2}$ shell for removal of microcystins. J. Am. Chem. Soc. 2008, 130, 28-29.

2. Anne-Laure Morel; Nikitenko, S. I.; Gionnet, K.; Wattiaux, A.; Labrugere, C.; Chevalier, B.; Simonoff, M. Sonochemical approach to the synthesis of $\mathrm{Fe}_{3} \mathrm{O}_{4} @ \mathrm{SiO}_{2}$ core-shell nanoparticles with tunable properties. ACS nano 2008, 2, 847-856.

3. Théry, C.; Clayton, A.; Amigorena, S.; Raposo, G., Isolation and characterization of exosomes from cell culture supernatants and biological Fluids. Curr. Protoc. Cell Biol., 2006; Vol. 30, pp 3.22.1-3.22.29. 4. Wan, Y.; Cheng, G.; Liu, X.; Hao, S.-J.; Nisic, M.; Zhu, C.-D.; Xia, Y.-Q.; Li, W.-Q.; Wang, Z.-G.; Zhang, W.-L.; Rice, S. J.; Sebastian, A.; Albert, I.; Belani, C. P.; Zheng, S.-Y. Rapid magnetic isolation of extracellular vesicles via lipid-based nanoprobes. Nat. Biomed. Eng. 2017, 1, 0058.

5. Huang, M.; Jin, Y.; Jiang, H.; Sun, X.; Chen, H.; Liu, B.; Wang, E.; Dong, S. Designed nanostructured Pt Film for electrocatalytic activities by underpotential deposition combined chemical replacement techniques. J. Phys. Chem. B 2005, 109, 15264-15271.

6. Huang, T.; Yang, J.; Zhou, W.; Liu, X.; Pan, Y.; Song, Y. Rapid identification of urinary tract infections based on ultrasensitive bacteria detection using volumetric bar-chart chip. Sens. Actuators, $B$ 2019, 298, 126885. 
7. Song, Y.; Zhang, Y.; Bernard, P. E.; Reuben, J. M.; Ueno, N. T.; Arlinghaus, R. B.; Zu, Y.; Qin, L. Multiplexed volumetric bar-chart chip for point-of-care diagnostics. Nat. Commun. 2012, 3, 1-9. 